\title{
FUNDAMENTOS TEÓRICOS DAS POLÍTICAS E PROGRAMAS DE DESIGN
}

\author{
Daniel Dutra Gomes \\ Universidade Federal de Pernambuco \\ Studio Daniel Dutra \\ contato@danieldutra.com.br \\ Kátia Medeiros de Araújo \\ Universidade Federal de Pernambuco \\ katia_araujo@hotmail.com.br
}

Resumo: A vocação política dos designers precisa avançar. Apesar da intervenção do governo no âmbito do design não ser um fenômeno novo, a dedicação dos pesquisadores sobre esta temática - políticas de design ainda é inepta. As miríades discussões e produtos da academia podem clarear o entendimento dos atores políticos sobre os desafios e obstáculos para o desenvolvimento do design. Este artigo apresenta uma revisão de fundamentos teóricos das políticas e programas de design. O trabalho inicia-se a partir de uma análise de diferentes definições sobre o escopo das políticas de design, propõe uma nova categorização para a temática, discute estratégias de governo para a promoção, suporte e educação de design e conclui com sete objetivos estratégicos para a gestão sistêmica de uma política de design.

Palavras-chave: política de design; tipos de políticas de design; programas de design; estratégia de design; revisão teórica.

\begin{abstract}
Designers' political vocation needs to move forward. Despite the fact that government intervention in the design sector is not a new phenomenon, the dedication of researchers on this subject-design policy is still inept. The myriads discussions and academics products can clarify the understanding of policy-makers about the challenges and obstacles to the development of design. This article presents a review of theoretical foundations of design policies and design programs. The study starts from an analysis of different definitions of design policies scope, it proposes a new categorization for the theme, discusses the government's strategies to design promotion, design support and design education and concludes seven strategic aims for managing design policies in a systemic way.
\end{abstract}

Keywords: design policy; design policies styles; design programs; design strategy; theorical review. 


\section{INTRODUÇÃO}

Este trabalho é fruto de reflexões em atividades de revisão bibliográfica e proposição teórica sobre políticas de design - intervenções do governo no setor de design em um país -, que ocorreram na execução do projeto de pesquisa 'Diagnóstico do Design na Cidade de Vitória: Estratégias para uma Política Local', no Programa de Pós-Graduação em Design na Universidade Federal de Pernambuco.

O estudo encontrou relatórios de governos e organizações registrando políticas e programas de design nacionais, mas, no entanto, identificou que levantamentos teóricos sobre esta temática ainda são escassos.

O objetivo deste artigo é discutir os fundamentos das políticas de design sobre quatro tópicos: a análise de diferentes definições sobre o escopo das políticas de design, a proposição de uma nova categorização para a temática, a discussão sobre estratégias para a promoção, suporte e educação de design e, ainda, a tese de sete objetivos estratégicos para a implantação de uma política de design sistêmica.

\section{POLÍTICAS DE DESIGN: DIFERENTES PERSPECTIVAS}

A primeira definição sobre políticas de design é atribuída ao professor inglês John Heskett, no final do século XX. Ele define a política de design como "a promoção do design como uma ferramenta para se obter vantagens econômicas e elevar a competitividade da economia nacional" (HESKETT, 1980, p.180).

Para Heskett (1980), as políticas de design visam marcar o setor de design no país, promovendo e avaliando a sua contribuição para a economia nacional. Nesse sentido, sua principal tarefa está em gerir a confiança nacional - governo, empresas e sociedade em geral - sobre o valor econômico do design.

Essa compreensão, atrelada ao contexto econômico dos países, acompanhou os trabalhos de outros pesquisadores ao redor do globo.

Darlie Koshy (2002), explica a popularização da temática como resultado de três questões econômicas globais:

1. O design como vantagem competitiva para as empresas e estratégia de desenvolvimento para as economias nacionais no mercado internacional;

2. A emergência do design através da expansão global da legislação de propriedade intelectual e industrial;

3. A convergência das novas tecnologias no desenvolvimento do design.

H. Alpay Er (1994; 2002) concorda com Heskett (1980; 2002) ao observar a relação entre o design e as políticas nacionais sob o ponto de vista econômico. Alpay Er define a política de design como "os esforços sistemáticos do governo com o objetivo de desenvolver os recursos de design nacionais e incentivar a sua utilização eficaz por partes das empresas a fim de aumentar as vantagens da economia nacional no mercado internacional" (ALPAY ER, 2002, p. 161).

Hytönen e Heikkinen (2003) enumeram quatro objetivos para a política de design em um país, todos relativos ao seu valor econômico, a saber:

1. Utilizar os recursos de design na formulação de estratégias para o progresso econômico dos setores públicos e privados;

2. Gerar emprego e outras oportunidade de negócios nacionais;

3. Aumentar o volume de exportações;

4. Melhorar a competividade das empresas no mercado internacional. 
Choi (2009) endossa o escopo econômico da temática. Em sua tese, a pesquisadora define as políticas de design como "intervenções governamentais para desenvolver os recursos de design nacionais a fim de melhorar a competitividade das organizações nacionais no mercado internacional" (CHOI, 2009, p. 35).

Posteriormente à discussão sobre o valor econômico do design nas políticas públicas nacionais, iniciou-se um outro debate com forte ênfase em questões sociais e ambientais, cuja absorção se deu especialmente nos países em desenvolvimento.

Amir (2004) questiona se o conceito tradicional da politica de design, baseado na estratégia de competitividade e crescimento econômico, é adequado para países em desenvolvimento. Em um artigo, o autor enfatiza que as políticas de design nestes países devem adotar uma abordagem ética focada em questões sociais e não apenas econômicas. Ele propõe que a formulação de políticas de design deve apontar para as necessidades da população. Nesse sentido, Amir (2004) recomenda três princípios:

1. A política de design deve ser elaborada como uma ferramenta social e cultural visando criar melhores condições de vida para a população;

2. O designer deve estar inserido em diferentes setores do serviço público e privado, não exclusivo ao desenvolvimento de artefatos;

3. Além do papel de liderança do governo, o desenvolvimento de uma política de design exige o envolvimento de diferentes partes interessadas: setor profissional de design, academia, empresas e sociedade civil.

A discussão de Sulfikar Amir é reforçada por Gisele Raulik-Murphy (2010) e Gabriel Patrocínio (2013) que, conscientes da realidade dos países em desenvolvimento, ampliam o escopo teórico da política de design. Ao redefinir a temática, Gisele e Gabriel, pesquisadores brasileiros, defendem em suas teses o valor social do design para o desenvolvimento de um país.

Políticas de Design são estratégias governamentais com o objetivo de desenvolver os recursos nacionais de design e fortalecer o seu uso efetivo no país. As políticas de design visam criar, portanto, um ambiente no qual o design e a criatividade possam prosperar e, nesse sentido, incentivam que empresas desenvolvam seus próprios produtos e serviços, fazendo uso da expertise de profissionais de design; promovem atuação dos designers no setor público a fim de melhorar os seus processos e, assim, garantir um serviço público de qualidade, acessível e inclusivo à população (RAULIK-MURPHY; CAWOOD; LEWIS, 2010, p. 54).

A compreensão de Gisele sobre as políticas de design vai ao encontro da máxima "design é mais do que um negócio". Assim, além de por em ordem a bagunça econômica, incrementar as vendas nacionais e aumentar as exportações no mercado internacional, o design é capaz de melhorar a vida cotidiana das pessoas.

Gabriel Patrocínio sintetiza este raciocínio e define que a "Política de Design trata de como o governo estabelece princípios para utilizar o design para alavancar o desenvolvimento social, econômico, industrial e regional" (PATROCíNIO, 2013, p. 19).

\subsection{Categorias de Políticas de Design}

No intuito de refletir sobre as diferenças na atuação dos governos no desenvolvimento de políticas do design, John Heskett (2001) propôs um diagrama identificando quatro tipos de política de design - estadista, central, remota e indireta. 
O trabalho de categorização de Heskett (2001) foi discutido, adaptado e ampliado por diferentes autores - Jacques Giard (1996); H. Alpay Er (2002); e Gisele Raulik-Murphy (2010). A Figura 1 e a lista de políticas de design apresentadas na página seguinte propõe uma nova representação esquemática, englobando as considerações dos autores supramencionados sobre o controle do governo sobre os programas de design e sobre a indústria nacional.

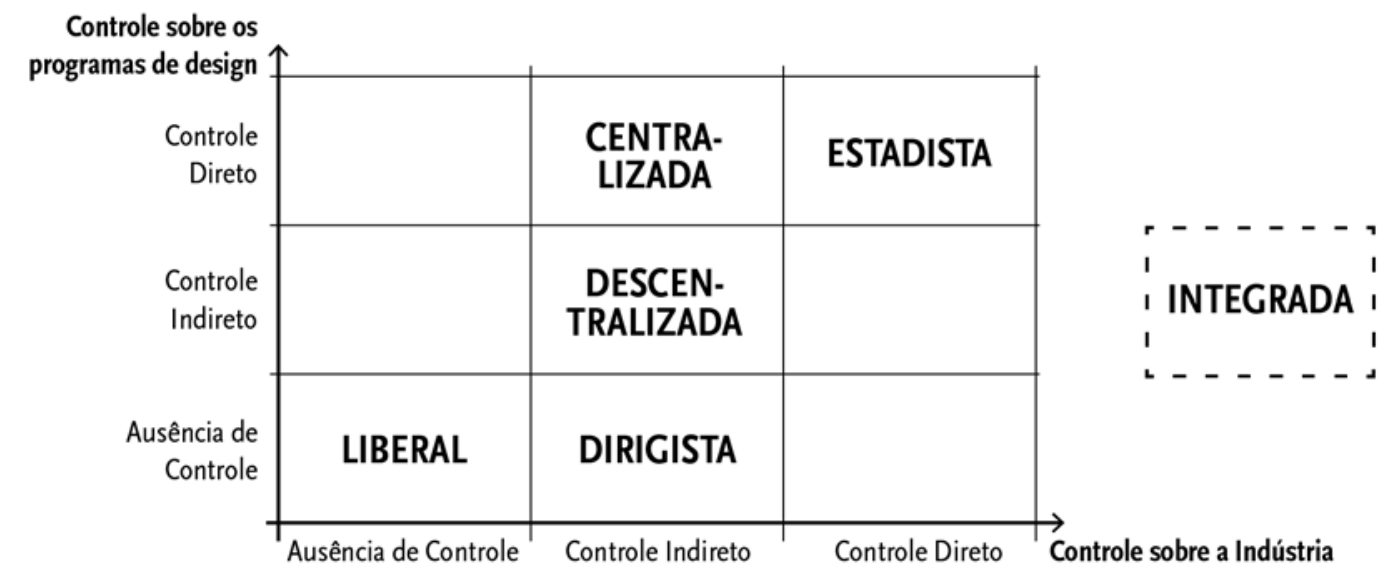

Figura 1 - Categorias de políticas de design.

Fonte: Elaborado pelo autor, com base em Giard (1996), Alpay Er (2002) e Raulik-Murphy (2010).

Política Estadista - política na qual os programas de design e a indústria nacional são administrados exclusivamente pelo governo. A política estadista, presente nos regimes comunistas, tem o intuito de garantir a autoridade totalitária do governo no controle da economia do país. Rússia, China e Cuba são exemplos desta categoria.

Política Centralizada - política na qual o governo desempenha um papel central no policy-making, principalmente na etapa de formulação dos programas de design, mas as entidades que implementam as estratégias não são propriedade do governo. Na política centralizada o governo não administra a indústria, por outro lado, conta com a sua cooperação para exercer o controle sobre a economia nacional. São exemplos desta categoria países como Japão, Cingapura, Taiwan e Coréia do Sul.

Política Descentralizada - tipologia na qual as entidades responsáveis pela formulação e implementação dos programas de design não são controlados pelo governo. Nesta categoria, o governo pode semi-financiar os programas, mas não exerce controle direto sobre elas. Reino Unido, Noruega, Dinamarca, África do Sul, Brasil e a maioria dos países do globo se encaixam nesta categoria.

Política Dirigista - política na qual não existe propriamente um plano nacional de design e o governo dirige os meios de produção pela apresentação de incentivos econômicos. O governo exerce um controle econômico indireto, promovendo práticas do seu interesse sem estatizar as empresas. A França é um exemplo desta categoria.

Política Liberal - o governo não tem uma política de design específica. No entanto, existem decisões governamentais cujos efeitos resvalam-se sobre o setor: legislações sobre responsabilidade técnica, propriedade industrial e outras leis e decretos que tem um efeito sobre a prática do design. A economia está nas mãos do livre mercado e o design, como qualquer outro setor, deve ser responsável pela sua sobrevivência. Estados Unidos e Alemanha são exemplos desta categoria. 
Política Integrada - a política de design está integrada a uma ou mais outras políticas macro. Assim, suas características variam de acordo com a política a qual está associada. A política integrada é uma prática emergente, tendo sido implementada principalmente em países europeus a partir de 1990. Este modelo oferece oportunidades para países que ainda não tem suas próprias políticas de design e desejam iniciar o desenvolvimento de seus programas como instrumentos de apoio às políticas econômicas, sociais, culturais ou de inovação. A Finlândia é um exemplo desta categoria, sua política de design está integrada ao sistema de inovação nacional.

\section{PROGRAMAS E ESTRATÉGIAS DE DESIGN}

Enquanto as políticas de design determinam uma visão estratégica e um plano para a utilização do design em um país, os programas de design são o meio pelo qual essas políticas são entregues.

Gisele Raulik-Murphy (2010) discute que os programas de design de governo podem tratar do setor privado ou público e ser categorizados em estratégias de promoção do design, de suporte de design e de educação para o design. A Tabela 1 apresenta resumidamente a classificação proposta por Raulik-Murphy:

Tabela 1 - Categorias de programas de design.

\begin{tabular}{lll}
\hline CATEGORIAS & PÚBLICO & FUNÇÃO \\
\hline Promoção & Público em geral & Promover o reconhecimento dos benefícios do design \\
\hline Suporte & Empresas & Prover recursos para o uso eficaz do design \\
\hline Educação & Designers & Garantir o ensino formal e treinamento profissional dos designers \\
\hline
\end{tabular}

Fonte: Adaptado pelo autor de Raulik-Murphy (2010).

Os programas de promoção, suporte e educação de design, elencados na Tabela 1 serão detalhadas nos tópicos seguintes.

\subsection{Programas de Promoção do Design}

As estratégias de promoção do design visam sensibilizar a sociedade sobre os benefícios do design (RAULIK-MURPHY; CAWOOD; LEWIS, 2010). Sua importância está em incentivar as empresas a investir em design, facilitar o acesso aos bons designers e formar na sociedade uma cultura de design (CAWOOD, 1997; COX, 2005; DAHLIN, SVENGREN, 1996). Os programas de promoção visam, também, difundir a identidade local no exterior ou educar internamente a população sobre o design (RAULIK, 2006).

Os programas de promoção de design variam principalmente quanto ao alcance das suas estratégias, podem visar um público interno (nacional) ou externo (internacional), dividido entre empresas, designers e sociedade em geral (Figura 2). 

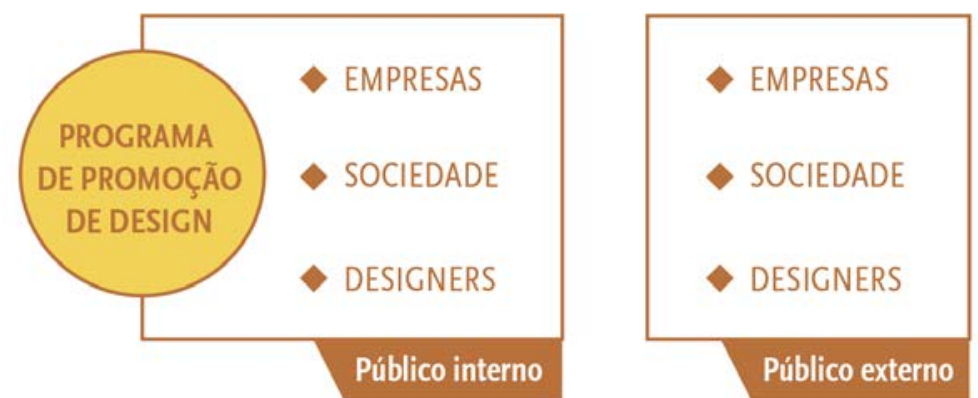

Figura 2 - 0 alcance dos programas de promoção de design.

Fonte: Elaborado pelo autor, com base na pesquisa realizada.

As iniciativas de promoção do design se constituem, de modo geral de premiações, concursos, mostras, exposições, feiras, publicações, conferências, workshops, seminários, certificações e outras campanhas, sendo muito semelhantes em todo mundo (RAULIK-MURPHY; CAWOOD; LEWIS, 2010).

As premiações e concursos estão sendo reconhecidos como estratégias eficientes para a promoção da cultura de design no mercado consumidor e nos meios empresarial e profissional. Ao premiar a produção dos profissionais, essas ações: geram visibilidade e credibilidade para os designers; incentivam o investimento em design por parte das empresas; valorizam e desafiam o aprimoramento do próprio setor profissional (KLOTZEL, 2007).

As premiações podem ser divididas entre nacionais e internacionais. Os prêmios nacionais de design, de maneira geral, promovem a competição profissional, estimulando a criatividade e a renovação do setor profissional de design. No Brasil, é possível citar o Prêmio Design Museu da Casa Brasileira, uma das premiações em design mais tradicionais em atividade no país.

Nos prêmios internacionais de design, por sua vez, os participantes procuram alcançar o mercado externo; garantir competitividade nacional no seu segmento; e reconhecimento e absorção de consumidor melhor informado e, assim, selecionar melhor os clientes. Alguns exemplos de premiações internacionais de design são: Ret Dot Awards, premiação internacional de design promovida na Alemanha e Design Management Europe Award (DME Award), premiação de gestão de design europeia.

Mostras, salões e exposições são uma outra forma comum de promover o design. Essas estratégias configuram-se como uma oportunidade de integração entre o público e os projetos de design. Normalmente, essas iniciativas estão vinculadas a algum concurso, como é o caso da Exposição de projetos do DME Award.

Os seminários e conferências de design estão, normalmente, vinculados a instituições de ensino, envolvendo mesas-redondas, palestras e debates, ou são promovidos por associações profissionais, agências de design. Seu alcance é limitado e a maioria não tem longevidade. Os Seminários Design to Business, promovido pelo Centro de Design do Paraná, no Brasil são um exemplo desta iniciativa.

Uma outra estratégia que tem se tornado comum nos programas de promoção é a oferta de um selo de design (certificações) para projetos, profissionais ou empresas, como é o caso de Made in Taiwan - campanha de promoção da produção de Taiwan. 


\subsection{Programas de Suporte de Design}

As estratégias de suporte de design, por sua vez, têm como objetivo prover os recursos necessários para o uso eficaz do design. Sua compreensão pode ser resumida em três palavras: prática, assessoria e indústria. São direcionadas principalmente a pequenas e médias empresas (PMEs), cuja integração do design em suas atividades é normalmente mais deficiente (RAULIK-MURPHY; CAWOOD; LEWIS, 2010).

Os benefícios do design ainda não são reconhecidos por todas as empresas, em especial pelas PMEs que permanecem céticas em relação ao custo-benefício do seu investimento em design. Outro obstáculo é a falta de recursos financeiros e humanos. A soma desses fatores - cultural e econômico, respectivamente - resulta em um cenário no qual os investimentos em design são vistos como custos que podem ser evitados usando as expertises internas de outros profissionais ou minimizados com mão-de-obra barata. $O$ resultado é a má qualidade de produtos e serviços e, em última instância, o insucesso empresarial (RAULIK-MURPHY; CAWOOD; LEWIS, 2010).

Segundo Raulik (2006), os programas de suporte de design apresentam-se em três formatos distintos, variando principalmente quanto à intensidade e duração da interação entre os envolvidos.

Programas de treinamento - englobam seminários, workshops, palestras, entre outras iniciativas pontuais de assessoria. Os programas de treinamento podem ocorrer individualmente ou em grupo e costumam ter custo reduzido, sendo bastante utilizados em programas para setores específicos da indústria. Exemplos: Programa Colour \& Trend, no País de Gales; e workshops Design Makes Difference, na Bélgica.

Assessoria de curta duração a empresas - caracteriza-se pela interatividade entre um assessor do programa, um designer e a empresa por um período curto que, normalmente, resulta na exposição dos projetos desenvolvidos. Exemplos: O Glasgow Collection, na Escócia; Criação Paraná, no Brasil; e Icebreaker, na Dinamarca.

Assessoria de longa duração a empresas - programas de suporte de design implementados em países que existe estabilidade e continuidade do apoio financeiro do governo. Este formato tem a vantagem de oferecer um serviço de design contínuo às empresas, permitindo a realização de projetos mais estratégicos. Exemplos: Design Wales, Centro de Design do País de Gales; no programa Design Innovation da Coréia do Sul; e no Design Program, na República Tcheca.

Mesmo com a variação de formato e duração, as assessorias de design nos programas de suporte costumam seguir um ciclo genérico (Figura 3) que pode ser descrito pelas seguintes etapas (RAULIK, 2006): 


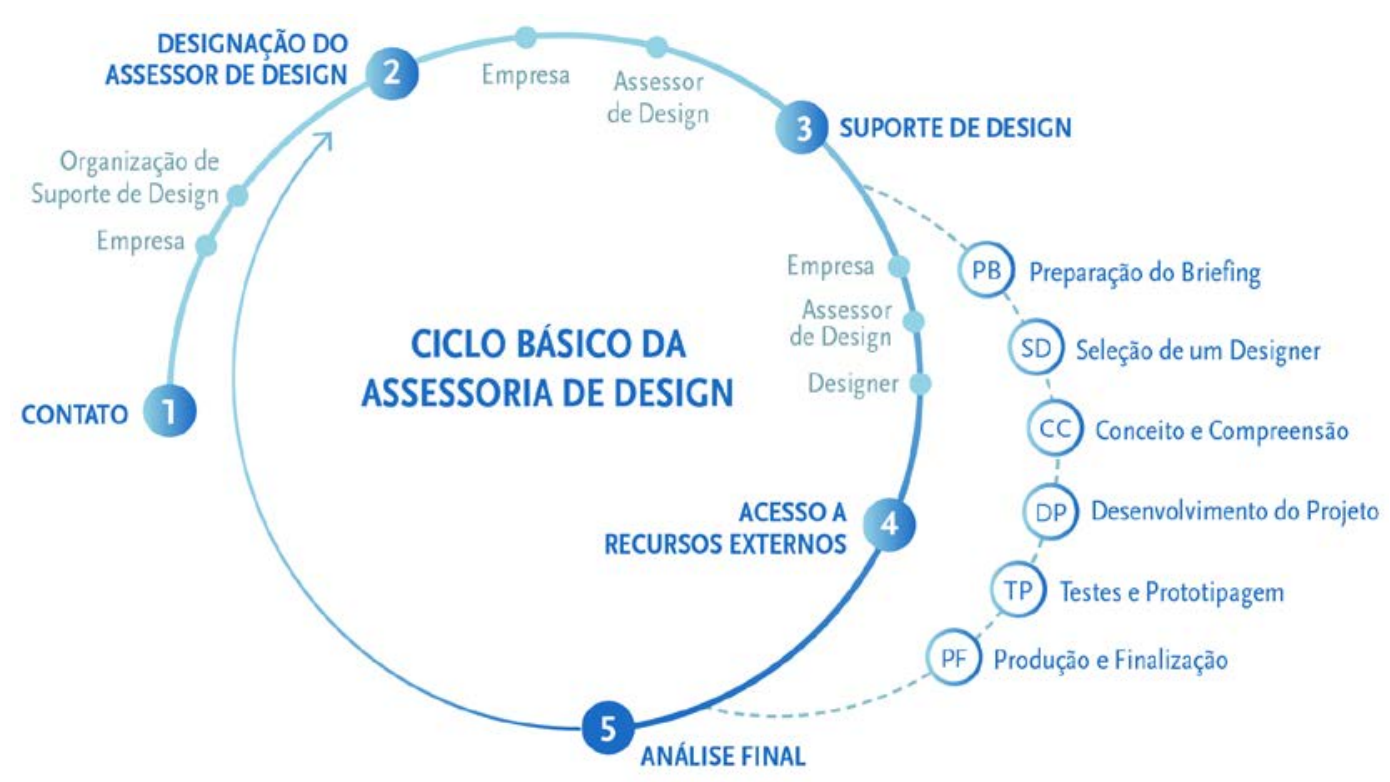

Figura 3 - Ciclo genérico do processo de assessoria de design.

Fonte: Elaborado pelo autor, com base na pesquisa realizada.

1. Contato - a empresa entra em contato com a instituição responsável pelo suporte de design, seja por iniciativa própria ou como resultado de alguma ação (visita de prospecção ou evento) da organização de suporte;

2. Designação do assessor de design - a instituição responsável pelo programa nomeia um assessor de design, também chamado de consultor, para atender a empresa. Deve-se selecionar àqueles que tiverem experiência com o tipo de negócio da empresa ou com a disciplina do projeto;

3. Suporte de design - uma vez iniciado o serviço de suporte, seguem-se as etapas de desenvolvimento que variam de programa para programa. As subetapas iniciais consistem na preparação do briefing e auxílio na seleção de um profissional ou empresa de design externa para trabalhar no projeto. Forma-se um trio: empresa, designer e assessoria. As etapas seguintes dividem-se entre: conceito; desenvolvimento do projeto; testes; e produção.

4. Acesso a recursos externos - cabe ao assessor facilita o acesso da empresa a recursos externos que sejam necessários ao projeto, como financiamentos, fornecedores e proteção de propriedade intelectual, por exemplo.

5. Análise final - com o término do projeto, o assessor deve concluir com a empresa a respeito dos benefícios obtidos com o uso do design, reconhecendo seu impacto nos negócios e mudanças na cultura da empresa.

Um programa de suporte deve tornar as empresas atendidas aptas a contratar um serviço de design e a acessar os recursos externos para os seus futuros projetos. É inevitável que dificuldades ainda aconteçam e, portanto, nestes casos, a empresa deve entrar em contato novamente com a instituição responsável pelo programa de suporte para sanar suas dúvidas, ou mesmo reiniciar o ciclo de assessoria (RAULIK, 2006).

A disponibilidade de financiamento do governo é uma questão crucial na formulação de um programa de suporte de design. Normalmente, sistemas de suporte com assessoria individual às empresas não são viáveis sem financiamento público. Quando o financiamento não é promovido pelo governo, as estratégias de suporte de 
design são limitadas a programas de treinamento, muitas vezes financiados pelas empresas e pelo próprio setor profissional de design (CAWOOD; LEWIS; RAULIK, 2004).

Um estudo (CAWOOD; LEWIS; RAULIK, 2004) revela três cenários contrastantes quanto à participação do governo nos programa de suporte de design: 1) O governo nacional não está comprometido de maneira alguma a apoiar financeiramente programas de suporte, postura reconhecida nos Estados Unidos e a França. 2) 0 financiamento público constante sustenta programas de suporte de design de longo prazo. Exemplos: País de Gales, Coréia do Sul e República Checa. 3) Cenário de instabilidade política nacional, presente em países como Dinamarca e Brasil, provoca a descontinuidade dos programas de suporte de design, forçando sua adaptação.

Existe um debate sobre as vantagens e desvantagens dos programas de promoção e suporte de design, que pode ser visualizado no esquema abaixo (Figura 4).

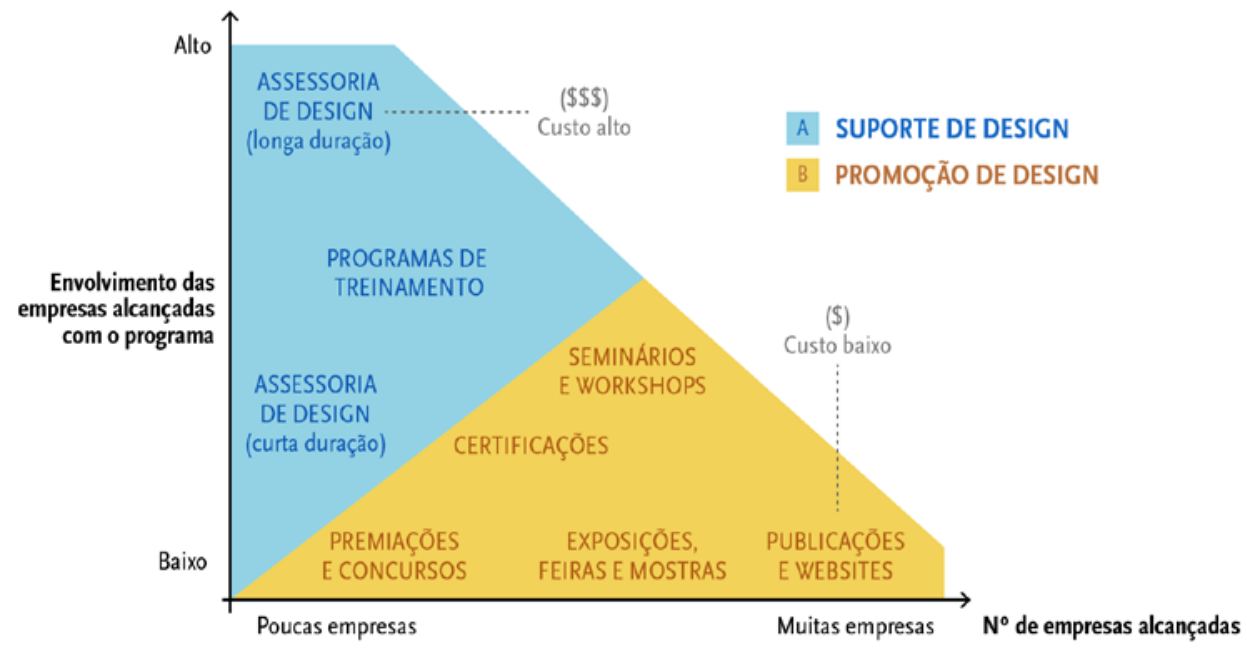

Figura 4 - Promoção de Design x Suporte de Design.

Fonte: Adaptado pelo autor de Bruce Tether (2006).

A execução de programas de promoção do design é mais comum do que a execução de programas de suporte. Em 2008, pesquisas (RAULIK; CAWOOD; LARSEN, 2008) mostraram que cerca 41 países ao redor do mundo investem em ações de promoção do design, enquanto apenas 27 realizam programas de suporte de design.

Geralmente, programas de promoção do design tem um custo menor quando comparado aos programas de suporte. A desvantagem das ações de promoção está na dificuldade de avaliar o impacto junto ao público, uma vez que seus resultados são percebidos a longo prazo junto à economia e à cultura de design (RAULIK, 2006).

A Figura 4 mostra que o alcance de programas de promoção do design é maior, o que permite ao governo a vantagem de atingir um número maior de empresas e indivíduos. Na Coréia do Sul, por exemplo, a mesma pesquisa revelou que o governo tomou essa iniciativa considerando-a mais barata (RAULIK; CAWOOD; LARSEN, 2008).

Por outro lado, o impacto de ações de suporte de design é percebido, a longo prazo, de maneira muito mais eficiente e concreta, mesmo que o número de empresas atingidas seja menor (RAULIK; CAWOOD; LARSEN, 2008).

Em um workshop internacional sobre programas de suporte de design, realizado em 2004 na cidade de Cardiff, no País de Gales, foi revelado que as estratégias de promoção do design são normalmente substituídas por estratégias de suporte de design com o tempo. Os delegados presentes no workshop endossaram 
que a promoção do design é importante e para sensibilização das empresas e da sociedade em geral sobre os benefícios do design, constituindo-se, portanto, como uma etapa inicial em qualquer política de design (CAWOOD; LEWIS; RAULIK, 2004).

Contudo, é importante argumentar que quando as ações de promoção do design se concentram apenas em exposições, premiações e publicações, é importante verificar se as empresas estão realmente recebendo a mensagem. Muitas vezes, as ações de promoção do design têm um alcance reduzido ao próprio setor profissional de design, não atingindo as empresas, muito menos a sociedade em geral.

O workshop também concluiu que o suporte de design entrega resultados mais tangíveis para as empresas, principalmente por conta das características das PMEs cujas atividades são majoritariamente gerenciadas por uma única pessoa, o proprietário da empresa. Para os delegados que estiveram no evento, a assessoria de design nesses casos é extremamente eficaz. Uma vez que o envolvimento do consultor e do designer é direto com o dono da empresa, o design é facilmente inserido na empresa de maneira estratégica (CAWOOD; LEWIS; RAULIK, 2004).

Um modelo de atuação que combina ações de promoção e suporte design também é considerado eficiente: programas de promoção a fim de sensibilizar as empresas a utilizar o design e programas de suporte a fim de iniciar na prática o design nos processos das empresas nacionais (CAWOOD; LEWIS; RAULIK, 2004).

\subsection{Programas de Educação do Design}

A Educação é parte integrante de uma política de design. Ela garante à sociedade a formação de profissionais de design em número, qualidade e nas expertises necessárias para suprir as demandas criadas pelos programas de pormoção e suporte de design (RAULIK-MURPHY; CAWOOD; LEWIS, 2010).

As políticas de design devem incorporar estratégias no âmbito da educação, visando melhores condições para a formação e atuação dos designers.

As principais estratégias de educação de design incluem o ensino formal e o treinamento profissional (RAULIK-MURPHY; CAWOOD; LEWIS, 2010). Outros programas visam a integração entre as escolas e a indústria, ou entre as escolas e problemas sociais, buscando alinhar o ensino com demandas atuais. É possível identificar, também, ações mais recentes que recomendam novos assuntos para os currículos dos cursos, incentivam a implantação de programas de pós-graduação em design ou mesmo a integração de disciplinas de design em outros cursos em diferentes níveis e modalidades de ensino (RAULIK, 2006).

Alguns países têm gerido uma política de educação de sucesso para o design. Mais uma vez, é possível citar a Coréia do Sul que, entre 1993 e 2002, aumentou o número de graduados em design de 15.000 para 36.000. O crescimento do número de graduados era uma estratégia segura, uma vez que o índice de desemprego no país era baixo, cerca de 3\% (RAULIK-MURPHY, CAWOOD, LEWIS, 2010).

Além disso, a política de educação somadas às ações de promoção do design na sociedade sul-coreana garantiu a formação de uma cultura de do design. Esse processo aumentou a demanda por produtos bem desenvolvidos, ou seja, o aumento do investimento em design por partes das empresas. Assim, foi gerado abertura no mercado por profissionais de design qualificados e aumento dos níveis salariais.

A política de design de outros países asiáticos, como Japão e China, têm se destacado pela elaboração de intervenções na estrutura curricular dos cursos visando alinhar o perfil do profissional de design com as necessidades das suas economias 
nacionais. Na Índia, um dos tópicos mais importantes da estratégia da política de design nacional é a manutenção do National Institute of Design, um Instituto Educacional Nacional de Design responsável por organizar o ensino de design no país.

\section{POLÍTICAS DE DESIGN: SETE OBJETIVOS ESTRATÉGICOS}

A partir do que foi discutido até, então, é possível elencar sete pontos estratégicos para a formulação e gestão de uma política de design, a saber:

1. Promover o desenvolvimento de uma cultura de design nacional;

2. Encorajar as empresas a investir em design;

3. Fornecer o suporte necessário para as empresas investirem em design;

4. Garantir um cenário econômico, fiscal e jurídico favorável ao design;

5. Formar designers pensantes, em número e qualidade, com apuro técnico e sensíveis às necessidades humanas;

6. Inserir o design nos diferentes setores do serviço público a fim de remodelar seus serviços e produtos;

7. Fomentar o diálogo constante entre governo, academia, empresas, setor profissional de design e sociedade.

Os governos têm, portanto, o desafio de propor programas que criem um ambiente favorável para o design prosperar - formando bons designers e facilitando a sua inserção na iniciativa pública e privada, responsáveis por trazer resultados reais significativos para a sociedade, em termos de qualidade de vida para as pessoas e competitividade econômica para as empresas.

Os sete tópicos tratam de uma consolidação teórica deste estudo a partir das leituras revisitadas e visam estabelecer objetivos estratégicos para a implantação de uma política de design nacional sistêmica. A utilização dessas diretrizes estratégicas para a formulação de programas e políticas de design deve observar o contexto político, social, econômico e cultural de cada país, buscando compreender como o design está inserido nessas esferas. Desse modo, o processo de formulação de políticas de design irá variar substancialmente, principalmente, no que diz respeito ao sumário de ações entregue, suas urgências e meios de implementação.

Além disso, não se deve pensar que as políticas de design são elaboradas de maneira isolada, exclusivamente a partir do diagnóstico do setor de design. Observar a descrição da política elaborada pelo governo é ao mesmo tempo direto e fácil, comparativamente ao esforço requerido para se compreender em termos mais gerais por que um Estado adotou tal política. E, por trás desta frase, existe um mundo de análise, autoridade e organização que pode parecer um tanto opaco e assustador para os acadêmicos que aventuram seus estudos nessa temática.

Às vezes, um governo pode anunciar as razões subjacentes a uma decisão, e essas podem até corresponder à verdade, mas, no entanto, podem não ser a forçamotriz decisória para a elaboração de uma política.

A análise de uma política pública inclui necessariamente considerar os atores envolvidos nos processos de tomada de decisão, sua capacidade de influenciar e agir. As decisões políticas são um reflexo tanto da vontade desimpedida dos tomadores de decisão governamental quanto das evidências de como essa vontade interagiu com as restrições geradas pelos outros atores, estruturas e ideias presentes em uma determinada conjuntura social. 


\section{CONSIDERAÇÕES FINAIS}

O debate sobre a eficácia dos diferentes programas e estratégias comentado ainda não foi concluído. É necessário que se realize uma análise sobre os custos de implementação dos programas de promoção e suporte comparado ao crescimento financeiro das empresas, como resultado do investimento em design.

Os casos citados tratam de iniciativas implantadas muito recentemente, cujos efeitos positivos e negativos do investimento em programas de promoção e suporte de design ainda não puderam ser mensurados, mas, no entanto, configuram-se como perspectivas para estudos vindouros.

Cada país mantém sua política de design de maneira distinta, variando suas justificativas, objetivos e meios de implementação. A diversidade de estruturas e estratégias para a solução dos problemas econômicos e sociais é uma forte característica desta temática, fato que reflete a natureza do próprio design.

\section{REFERÊNCIAS}

ALPAY ER, H. The Emergence and Developmental Patterns of Industrial Design in Newly Industrialised Countries with Particular Reference to Turkey. Tese (doutorado). Manchester: Institute of Advanced Studies, Manchester Metropolitan University, 1994.

ALPAY ER, H. Does Design Policy Matter? The Case of Turkey in a Conceptual Framework. ICSID, KIDP. World Design Forum Proceedings. Seongnam: Design Policy and Global Network, 2002. p. 160-191.

AMIR, Sulfikar. Rethinking Design Policy in the Third World. Design Issues. v. 20, n. 4, 2004. p. 68-75.

BONSIEPE, Gui. Design, Cultura e Sociedade. São Paulo: Blucher, 2011.

CARDOSO, Rafael. Design para um Mundo Complexo. São Paulo: Cosac Naify, 2012.

CAWOOD, Gavin. Design Innovation and Culture in SMEs. Design Management

Review. v. 8, n. 4, 1997. p. 66-70.

CAWOOD, Gavin; LEWIS, Alan; RAULIK, Gisele. International Perspectives on Design Support for SMEs. Design Management Review. v. 15, n. 4, 2004. p. 71-76.

CHOI, Youngok. A Comparative Study of National Design Policy in the UK and South Korea. Tese (doutorado). Lancaster: Institute for the Contemporary Arts, Lancaster University, 2009.

COX, George. Review of Creativity in Business: building on the UK's strengths. London: HM Treasury, 2005.

DAHLIN, Torsten; SVENGREN, Lisbeth. Strategic Issues for a Design Support Organisation: The Swedish Industrial Design Foundation. In Design Management Review. v. 7, n. 3, 1996. p. 37-42.

GIARD, Jacques. Canadian Design and the National Agenda: Towards the Year 2005. Design Management Journal. v. 7, n. 3, 1996. p. 27-31.

HESKETT, John. Industrial Design. Londres: Thames \& Hudson, 1980.

HESKETT, John (2001). Design Policy - Notes and Handouts. Paper presented at the Masters Course. Chicago: Illinois Institute of Technology, Institute of Design, 2001. 
HYTÖNEN, Jaana; HEIKKINEN, Hanna. Design Policy and Promotion Programmes in Selected Countries and Regions. Helsinki, Finland: Designium, The New Centre of Innovation in Design in the University of Art and Design in Helsinki, 2003.

KLOTZEL, Ruth. Concursos de Design. Portal DesignBrasil, 2007. Disponível em: http://goo.gl/k7N7b7. Acesso em 10 jan. 2015.

KOSHY, Darlie. Broadbanding Design Policy and Promotion: Focus on the Region and India. ICSID, KIDP. World Design Forum Proceedings. Seongnam: Design Policy and Global Network, 2002. p. 141-159.

PATROCINIO, Gabriel Henrique Torres do. The impact of European design policies and their implications on the development of a framework to support future Brazilian design policies. Tese (doutorado). Bedfordshire: Cranfield University, 2013.

RAULIK, Gisele. Panorama Internacional das Políticas de Promoção e Incentivo ao Design. Brasília: Ministério do Desenvolvimento, Indústria e Comércio Exterior, 2006.

RAULIK, Gisele; CAWOOD, Gavin; LARSEN, Povl. National Design Strategies and Country Competitive Economic Advantage. The Design Journal. v. 11, n. 2, 2008. p. 119-135.

RAULIK-MURPHY, Gisele. A Comparative Analysis of Strategies for Design Promotion in Different National Contexts. Tese (doutorado). Cardiff: The University of Wales, 2010.

RAULIK-MURPHY, Gisele; CAWOOD, Gavin; LEWIS, Alan. Design Policy: An Introduction to What Matters. Design Management Review. v. 21, n. 4, 2010. p. 52-59.

TETHER, Bruce (2006). Evaluating the Impacts of Design Support. In SEEdesign Bulletin. National Centre for Product Design \& Development Research (PDR). n. 3, setembro de 2006. p. 8-10. Cardiff, Reino Unido. 